\title{
Plant-Based Synthesis of Zinc Oxide Nanoparticles (ZnO-NPs) Using Aqueous Leaf Extract of Aquilegia pubiflora: Their Antiproliferative Activity against HepG2 Cells Inducing Reactive Oxygen Species and Other In Vitro Properties
}

\author{
Hasnain Jan $\mathbb{D}^{1},{ }^{1}$ Muzamil Shah, ${ }^{1}$ Anisa Andleeb, ${ }^{1}$ Shah Faisal, ${ }^{2}$ Aishma Khattak, ${ }^{3}$ \\ Muhammad Rizwan, ${ }^{4}$ Samantha Drouet, ${ }^{5}$ Christophe Hano, ${ }^{5}$ and Bilal Haider Abbasi (iD ${ }^{1}$ \\ ${ }^{1}$ Department of Biotechnology, Quaid-i-Azam University, Islamabad 45320, Pakistan \\ ${ }^{2}$ Institute of Biotechnology and Microbiology, Bacha Khan University, KPK, Pakistan \\ ${ }^{3}$ Department of Bioinformatics, Shaheed Benazir University Peshawar, KPK, Pakistan \\ ${ }^{4}$ Centre for Biotechnology and Microbiology, University of Swat, KPK, Pakistan \\ ${ }^{5}$ Laboratoire de Biologie des Ligneux et des Grandes Cultures (LBLGC), INRA USC1328 Université d' Orléans, Cedex 2, France
}

Correspondence should be addressed to Hasnain Jan; hasnainjan@bs.qau.edu.pk and Bilal Haider Abbasi; bhabbasi@qau.edu.pk

Received 16 April 2021; Revised 30 June 2021; Accepted 2 August 2021; Published 18 August 2021

Academic Editor: Antonella Smeriglio

Copyright ( 2021 Hasnain Jan et al. This is an open access article distributed under the Creative Commons Attribution License, which permits unrestricted use, distribution, and reproduction in any medium, provided the original work is properly cited.

\begin{abstract}
The anti-cancer, anti-aging, anti-inflammatory, antioxidant, and anti-diabetic effects of zinc oxide nanoparticles (ZnO-NPs) produced from aqueous leaf extract of Aquilegia pubiflora were evaluated in this study. Several methods were used to characterize ZnO-NPs, including SEM, FTIR, XRD, DLS, PL, Raman, and HPLC. The nanoparticles that had a size of $34.23 \mathrm{~nm}$ as well as a strong aqueous dispersion potential were highly pure, spherical or elliptical in form, and had a mean size of $34.23 \mathrm{~nm}$. According to FTIR and HPLC studies, the flavonoids and hydroxycinnamic acid derivatives were successfully capped. Synthesized $\mathrm{ZnO}-\mathrm{NPs}$ in water have a zeta potential of $-18.4 \mathrm{mV}$, showing that they are stable solutions. The ZnO-NPs proved to be highly toxic for the HepG2 cell line and showed a reduced cell viability of $23.68 \pm 2.1 \%$ after 24 hours of ZnO-NP treatment. ZnO-NPs also showed excellent inhibitory potential against the enzymes acetylcholinesterase $\left(\mathrm{IC}_{50}: 102 \mu \mathrm{g} / \mathrm{mL}\right)$ and butyrylcholinesterase $\left(\mathrm{IC}_{50}: 125 \mu \mathrm{g} / \mathrm{mL}\right.$ ) which are involved in Alzheimer's disease. Overall, the enzymes involved in aging, diabetes, and inflammation showed a moderate inhibitory response to ZnO-NPs. Given these findings, these biosynthesized ZnO-NPs could be a good option for the cure of deadly diseases such as cancer, diabetes, Alzheimer's, and other inflammatory diseases due to their strong anticancer potential and efficient antioxidant properties.
\end{abstract}

\section{Introduction}

Nanotechnology is an interdisciplinary science that encompasses several disciplines, including electronics, biomaterials, and medicine. A number of techniques, including physical, chemical, and biological processes, can be used to create nanomaterials with useful characteristics as tiny as $10-100 \mathrm{~nm}$ in size $[1,2]$. Because of their large surface area, small size, thermal conductivity, shape, surface morphology, charge, zeta potential, and crystal structure [3], nanoscale materials have piqued the interest of scientists, allowing them to be integrated into biotechnological and biomedical sectors, particularly for the cure of deadly diseases, i.e., cancer and Alzheimer's $[4,5]$. Traditional methods (chemical and physical) for producing nanoparticles have numerous limitations [6], including long-term processing, high prices, tedious procedures, hazardous by-products, and in particular the usage of poisonous chemicals [7]. However, due of its cost effectiveness, environmental friendliness, biocompatibility, convenience of use, and quick synthesis procedures, green synthesis is a favored technique for nanoparticle production $[8,9]$. NPs can be biosynthesized by a variety of biological entities, 
including cyanobacteria, fungus, actinomycetes, bacteria, algae, and plants. Green-synthesized nanoparticles offer a new perspective as a delivery vehicle, for specific and safer drug delivery, a promising alternative to cancer drugs. Several NPs have been synthesized by green synthesis, such as $\mathrm{Ag}, \mathrm{Cu}, \mathrm{Au}, \mathrm{ZnO}, \mathrm{Se}$, and $\mathrm{CuO}$, and many others that have unique biological activities [10-13].

Due to its multiple uses in several technical sectors, metal oxide NPs have been actively investigated during the last decade. ZnO-NPs are an interesting inorganic material with a varied series of uses in a variety of fields, including semiconductors, energy conservation, textiles, cosmetics, electronics, health care, catalysis, and chemical sensors [14-16]. $\mathrm{ZnO}-\mathrm{NPs}$ are nontoxic, biocompatible, and cheap and have a wide range of biological uses, including targeted drug delivery, anti-inflammatory, wound healing, antimicrobial agents, anti-cancer, and bioimaging [17]. ZnO-NPs are also utilized in beauty care products and sunscreens due to their effective UV absorption capabilities [18]. The use of ZnO-NPs as additives in nutritional products was certified a few years ago to increase growth performance, improve antioxidant properties, and boost the quality of eggs and chickens [19].

Metal oxide (MNPs) may be produced in a variety of ways (chemical, physical, and biosynthetic) and have a diverse set of characteristics and uses. Green synthesis covers the synthesis from algae, fungus, plants, bacteria, and other microorganisms. They enable the large-scale manufacturing of $\mathrm{ZnO}$-NPs devoid of contaminants [20]. Plant parts including the leaf, stem, root, fruit, and seed have been utilized to generate $\mathrm{ZnO}$-NPs because of the specific phytochemicals they produce. Natural extracts of plant components offer a low-cost and environmentally beneficial alternative to using intermediary base groups [21]. Secondary plant compounds found in plant extracts function as both reducing agents and capping or stabilizing agents. Metal ions or metal oxides are reduced to zero valence metal NPs in bioreduction with the aid of plant-secreted phytochemicals such as polyphenolic compounds, alkaloids, polysaccharides, amino acids, vitamins, and terpenoids [20]. Plants of the Lamiaceae family such as Vitex negundo, Plectranthus amboinicus, and Anisochilus carnosus have been extensively researched, revealing NP production in a variety of sizes and forms, including rod-shaped, hexagonal, quasispherical, and spherical with agglomerates. The results clearly showed that the size of produced NPs reduces as the content of a plant extract increases. For the most part, the leaves of $A$. indica of the Meliaceae family have been utilized in the synthesis of ZnO-NPs. All tests revealed NPs with spherical and hexagonal disc shapes, as verified by XRD and TEM analyses. Alkane, amide, carbonate, alcohol, amine, and carboxylic acid were shown to be effective capping agents in these investigations. Furthermore, these synthesized NPs were also proved efficient in various biomedical applications like antimicrobial, anti-cancer, anti-diabetic, and antioxidants [20].

Aquilegia pubiflora is a medicinally valuable herb, which belongs to the Ranunculaceae family and is widespread in the Himalayas of India, northern Pakistan, and Afghanistan. This herbaceous plant is commonly called as hairy flowered columbine or Himalayan columbine but known locally as
Thandi buti or Domba [22]. This species possesses many important pharmacological and medicinal properties including astringent, dyspepsia, cardiotonic, antiasthmatic, antipyretic, stimulant, and antijaundice. This plant's dried roots have been used to cure eye disorders, snakebites, homeopathy, inflammation, and toothaches and particularly for the nervous system [23]. A recent study found that the methanolic extract of Aquilegia pubiflora exhibits effective erythroid induction activity, indicating that this plant might be a source of fetal hemoglobin producing phytocompounds and could be utilized to treat $\beta$-thalassemia [24]. Moreover, Aquilegia pubiflora was mainly used for the treatment of influenza, skin burns, wound healing, jaundice, and gynecology, circulatory, and cardiovascular disease [25].

Here, we disclose the bio-assisted synthesis of $\mathrm{ZnO}-\mathrm{NPs}$ through an ecofriendly approach using aqueous extracts of Aquilegia pubiflora as an efficient oxidizing/reducing and capping agent. The biosynthesis of $\mathrm{ZnO}-\mathrm{NPs}$ has already been reported; however, their diverse biological properties including anti-Alzheimer's, antidiabetic, antiaging, and anticancer activities have been less exposed. The aim of the present study is therefore to investigate the biological effects of synthesized ZnO-NPs [7]. HPLC, FTIR, XRD, SEM, DLS, Raman, and PL were used to characterize the ZnO-NPs as we previously reported [26, 27]. The well-characterized $\mathrm{ZnO}-\mathrm{NPs}$ were examined for their biological activities, including anti-inflammatory activity, anti-aging, anti-diabetic, and antioxidant activities. The anti-Alzheimer and anti-diabetic effects of $\mathrm{ZnO}$-NPs were also screened, and the in vitro cytotoxic potential against cancer cell was examined for their possible application in the biomedical field.

\section{Materials and Methods}

2.1. Plant Identification and Extraction. The leaves of Aquilegia pubiflora were collected in the Swat area of Pakistan and determined to be disease-free and healthy. Plant identification and verification were carried out by Professor Mushtaq Ahmad of the Herbarium of the Department of Plant Sciences at Quaid-i-Azam University in Pakistan. The collected leaves were cut into tiny bits and properly washed with tap water to remove contaminants and dust spores. The cleaned leaves were stored in a closed room (at $25^{\circ} \mathrm{C}$ ) for around 7 days to dry. In a sterile Willy mill, the dried leaves were crushed into a fine powder. To prepare the extract, $30 \mathrm{~g}$ of fine powder was mixed with $200 \mathrm{~mL}$ distilled water in a $500 \mathrm{~mL}$ flask, sonicated for 10 minutes, and maintained in a shaking incubator at $200 \mathrm{rpm}$ and $37^{\circ} \mathrm{C}$ for two days. To get rid of any leftovers, the extract was filtered twice with nylon paper and then three times with Whatman No. 1 filter paper.

2.2. Biosynthesis of $\mathrm{ZnO}$ Nanoparticles. For the green synthesis of ZnO-NPs, the conventional process from Thema et al. was followed, with slight modifications to the extract and salt concentrations [28]. Before and after dissolving the aqueous extract with the precursor salt, $\mathrm{UV}$ and $\mathrm{pH}$ were monitored. $100 \mathrm{~mL}$ of extract was mixed with $6.0 \mathrm{~g}$ of zinc acetate dihydrate salt and swirled for 2 hours at $60^{\circ} \mathrm{C}$ on a magnetic stirrer. Only after reaction occurs, the temperature is lowered for 
10 minutes at $25^{\circ} \mathrm{C}$ upon being centrifuged at $10,000 \mathrm{rpm}$ (HERMLE Z326 K). The solution was separated, and the leftover pellet was rinsed multiple times with sterile water before being placed on a clean Petri plate and dried in the oven at $80^{\circ} \mathrm{C}$. The dried materials were ground to a powdered form in a clean grinder and pulverized at $500^{\circ} \mathrm{C}$ for 2 hours to remove any impurities. For eventual physical characterization and biomedical uses, the annealed powder was put in a sealed sample vial, labeled, and stored.

2.3. Characterization of Biosynthesized $\mathrm{ZnO}-\mathrm{NPs}$. As previously reported, the morphological, structural, and vibrational physiognomies of obtained $\mathrm{ZnO}-\mathrm{NPs}$ were investigated utilizing a variety of characterization methods such as HPLC, FTIR, XRD, SEM, DLS, Raman, and PL [27]. HPLC and Fourier transform infrared spectroscopy (FTIR) $\left(400-4000 \mathrm{~cm}^{-1}\right)$ were used to identify phytochemicals and associated functional groups on $\mathrm{ZnO}-\mathrm{NPs}$. XRD was used to verify the good crystallinity, phase recognition, and homogeneity of $\mathrm{ZnO}-$ NPs (Model-D8 Advance, Germany). To test the stability of $\mathrm{ZnO}-\mathrm{NPs}$ after processing, the dispersal sustainability of the particles in purified water with various $\mathrm{pH}$ values was visually analyzed. SEM was used to investigate the morphological characteristics of particles. DLS was used to identify the optimum charge and stability of $\mathrm{ZnO}-\mathrm{NPs}$. Photoluminescence (PL) and Raman spectroscopy were used to identify oxygen vacancies and vibrational modes [27].

2.4. Antidiabetic Assays. To explore the anti-diabetic ability of biosynthesized ZnO-NPs, both $\alpha$-glucosidase inhibition and $\alpha$-amylase bioassays were performed.

2.4.1. $\alpha$-Amylase Inhibition Assay. The $\alpha$-amylase inhibiting action of $\mathrm{ZnO}-\mathrm{NPs}$ was evaluated using the methodology of Zohra et al. with minor variations in NP concentrations [29]. For this test, a 96-well microplate was utilized, and $10 \mathrm{~L}$ of $\mathrm{ZnO}-\mathrm{NPs}$ was added to each well, followed by $15 \mathrm{~L}$ of sodium phosphate buffer ( $\mathrm{pH} 6.9), 25 \mathrm{~mL}$ of alpha-amylase, and $40 \mathrm{~mL}$ of starch solution. After 30 minutes of incubation at $50^{\circ} \mathrm{C}$, the reaction was halted by adding $20 \mathrm{~mL}$ of $1 \mathrm{M} \mathrm{HCl}$ and $90 \mathrm{~L}$ of iodine solution. Like a control treatment, acarbose was utilized, while DMSO is being used as a negative control. A microplate reader was used to detect absorbance at $540 \mathrm{~nm}$. The \% inhibition of alpha-amylase by samples was determined using the following formula. The experiment was carried out in triplicate and twice.

$$
\begin{aligned}
& \text { \%Enzyme inhibition } \\
& \qquad=\left(\frac{\text { Abs Sample }- \text { Abs negative control }}{\text { Abs blank }- \text { Abs negative control }}\right) \times 100 .
\end{aligned}
$$

2.4.2. $\alpha$-Glucosidase Inhibition Assay. The anti-diabetic potential of $\mathrm{ZnO}-\mathrm{NPs}$ was additionally evaluated utilizing previously reported protocol by Saratale et al. with minor changes in sample concentration $[30,31]$. At $\mathrm{pH} 6.8$, $50 \mathrm{~mL}$ of phosphate buffer and $p$-nitrophenyl alpha-Dglucopyranoside substrate solution was produced, and $100 \mathrm{mg}$ of BSA was added. $10 \mathrm{~mL}$ of $\mathrm{ZnO}-\mathrm{NPs}$ was preincubated with $250 \mathrm{~L} \alpha$-glucosidase $(0.15$ units $/ \mathrm{mL})$ at $37^{\circ} \mathrm{C}$ for 5 minutes. The master mixture was kept at $37^{\circ} \mathrm{C}$ for 15 minutes. After simply adding $2 \mathrm{~mL}$ of $200 \mathrm{mM} \mathrm{Na}_{2} \mathrm{CO}_{3}$ solution, the process was stopped. The absorbance of $p$ nitrophenol generated was measured at $400 \mathrm{~nm}$ using a $\mathrm{UV}-\mathrm{V}$ is spectrophotometer. Using the formula below, the $\%$ inhibition of $\alpha$-glucosidase by samples was calculated. In the experiment, acarbose was used as a positive control and carried out in triplicate and repeated twice.

$$
\begin{aligned}
& \text { \%Enzyme inhibition } \\
& \qquad=\left(\frac{\text { Abs Sample }- \text { Abs negative control }}{\text { Abs blank }- \text { Abs negative control }}\right) \times 100 \text {. }
\end{aligned}
$$

\subsection{Antioxidant Assays}

2.5.1. Total Antioxidant Capacity (TAC) Determination. The TAC potential of ZnO-NPs was calculated by a previously described methodology by Shah et al., with slight modifications in applied concentration [31, 32]. Using a micropipette, $100 \mathrm{~L}$ of ZnO-NPs was added to the Eppendorf tubes. Thereafter, Eppendorf tubes comprising $\mathrm{ZnO}-\mathrm{NPs}$ received $900 \mathrm{~mL}$ of TAC reagent $(0.6 \mathrm{M}$ sulfuric acid, $28 \mathrm{mM}$ sodium phosphate, and $4 \mathrm{mM}$ ammonium molybdate in $50 \mathrm{~mL}$ $\left.\mathrm{dH}_{2} 0\right)$. The solution was allowed to cool to room temperature after 2.5 hours in a water bath at $90^{\circ} \mathrm{C}$. A spectrophotometer reader was used to quantify the reagent absorbance at $630 \mathrm{~nm}$. The amount of ascorbic acid equivalent (AAE) per milligram of analyte was used to calculate TAC. The test was repeated three times in total.

2.5.2. Total Reducing Power (TRP) Determination. The total reduction power of $\mathrm{ZnO}-\mathrm{NPs}$ was tested using the approach outlined by Nazir et al. [32, 33]. $100 \mathrm{~mL}$ of ZnO-NPs was combined with $400 \mathrm{~mL}$ of $\mathrm{C}_{6} \mathrm{~N}_{6} \mathrm{FeK}_{3}$ and 0.2 molar phosphate buffer ( $\mathrm{pH}$ 6.6) in Eppendorf tubes and maintained for 30 minutes at $55^{\circ} \mathrm{C}$ in a water bath. The solution was centrifuged for 8 minutes at $1200 \mathrm{rpm}$ with $400 \mathrm{~mL}$ of $\mathrm{C}_{2} \mathrm{HCl}_{3} \mathrm{O}_{2}$ added to each Eppendorf tube. The supernatant $(140 \mathrm{~mL})$ from each combination was poured into the wells of a 96well plate containing $60 \mathrm{~mL}$ ferric cyanide solution. A spectrophotometer reader was used to quantify the reagent absorbance at $630 \mathrm{~nm}$. The amount of ascorbic acid equivalent (AAE) per milligram of analyte was used to calculate TRP. The test was repeated three times in total.

2.5.3. Free Radical Scavenging Assay (FRSA). The established protocol of Ahmed et al. evaluated the potential free radical scavenging capability of $\mathrm{ZnO}-\mathrm{NPs}$ using a previously reported protocol $[34,35]$. To assess the antioxidant capacity of test samples, DPPH reagents at concentrations ranging from $12.5 \mathrm{~mL}$ to $400 \mathrm{~mL}$ were employed. A 96-well plate was filled with $10 \mathrm{~mL}$ of $\mathrm{ZnO}-\mathrm{NPs}$, and $90 \mathrm{~mL}$ of $\mathrm{DPPH}$ reagent was applied to each well containing $\mathrm{ZnO}-\mathrm{NPs}$. The positive control was ascorbic acid, while the negative control was DMSO. A microplate detector was used to measure the absorbance of the reaction mixture at $515 \mathrm{~nm}$.

2.5.4. ABTS Assay. The ABTS test, commonly identified as the Trolox antioxidant assay, was performed using the 
procedure of Faisal et al. with minor changes in applied concentrations $[33,36]$. An ABTS solution for the reaction was made by combining $2.45 \mathrm{mM}$ potassium per sulphate with $7 \mathrm{mM}$ of ABTS chemical, subsequently 16 hours in the dark incubation. Upon mixing with test sample, the resulting tubes were incubated in the darkness for 15 minutes at $25^{\circ} \mathrm{C}$. The absorbance of the test sample was measured at $734 \mathrm{~nm}$ using the Microplate Reader (BioTek ELX800). Negative and positive controls were employed, respectively, with DMSO and Trolox. The antioxidant potential of the samples was measured in TEAC, and the experiment was repeated three times.

2.6. Anti-Alzheimer's Activity. Inhibiting the enzymes butyrylcholinesterase (BChE) and acetylcholinesterase (AChE) is a possible therapeutic target for Alzheimer's disease. The inhibitory ability of ZnO-NPs against AChE and BChE enzymes was evaluated using a slightly modified Elman's technique in terms of NP concentration and dosages, as previously published by Imran et al. [37, 38]. From the test sample, a concentration scale ranging from $12.5 \mu \mathrm{g} / \mathrm{mL}$ to $200 \mu \mathrm{g} / \mathrm{mL}$ was used. In brief, $\mathrm{ZnO}$-NPs are distributed in a phosphate-buffered saline solution (PBS). The ultimate enzyme concentration for AChE was $0.03 \mathrm{U} / \mathrm{mL}$, and for $\mathrm{BChE}$, it was $0.01 \mathrm{U} / \mathrm{mL}$. The reaction mixture was supplemented with DTNB $(0.00022 \mathrm{M})$, acetylcholine iodide (ATchI; 0.0005 M), and butyrylcholine iodide (BTchI; $0.0005 \mathrm{M})$ produced in filtered water at $8^{\circ} \mathrm{C}$. Galantamine hydrobromide (Sigma; GI660) produced in methanol was employed as a positive control in the experiment, and the reaction mixture stripped of the test sample was used as a negative control. The anticholinesterase activity is established on the splitting of ATchI into AChE and BTchI into $\mathrm{BChE}$, which results in the production of the yellowcolored products. Using a spectrophotometer, the absorbance was eventually measured at $412 \mathrm{~nm}$. Galantamine and $\mathrm{ZnO}-\mathrm{NPs}$ have estimations for percent enzyme activity and percent enzyme inhibition with a temporal shift in the absorption rate. The following formulae were used to compute the percent enzyme inhibition.

$$
\begin{gathered}
V=\frac{\Delta A b s}{\Delta t}, \\
\text { Inhibition }(\%)=100-\text { Enzyme activity }(\%), \\
\text { Enzyme activity }(\%)=\left(\frac{V}{V_{\max }}\right) \times 100 .
\end{gathered}
$$

\subsection{Anti-Inflammatory Activities}

2.7.1. Against COX-1 and COX-2. ZnO-NPs were evaluated for their ability to inhibit COX-1 (Ovine Kit 701050) and COX-2 (Human Kit 701050). As a positive control, ibuprofen $10 \mathrm{M}$ was used, and arachidonic $(1.1 \mathrm{mM})$ was used as a substrate. Both COX peroxidase components were measured in accordance with the kit's manufacturer's instructions. The test was carried out on a 96-well plate in triplicate and was repeated twice.
2.7.2. Against 15-LOX. ZnO-NPs were tested for their ability to inhibit 15-LOX (760700 kit, Cayman France). $100 \mathrm{M}$ NDGA was employed as a positive control, whereas $10 \mathrm{M}$ $\mathrm{C}_{20} \mathrm{H}_{32} \mathrm{O}_{2}$ was used as a substrate. Hydroperoxides are formed as a result of lipooxygenation, and their concentration was measured using a 15-lipooxygenase standard in $10 \mathrm{mM}$ Tris- $\mathrm{HCl}$ buffer at $7.4 \mathrm{pH}$ filter supplied with the kit. In a 96-well plate, $\mathrm{ZnO}-\mathrm{NPs}$ and enzyme are mixed together and incubated for 5 minutes. The 5 -minute incubation was followed by 15 -minute incubation after the addition of the substrate and a 5-minute incubation period after the addition of the chromogen. Using a Synergy II reader, the absorbance was measured at $590 \mathrm{~nm}$ (BioTek Instruments, Colmar, France).

2.7.3. Against Secretory Phospholipase A2 (sPLA2). An assay kit (10004883, Cayman Chem., France) was used to test the inhibitory ability of $\mathrm{ZnO}-\mathrm{NPs}$ against sPLA2. $1.44 \mathrm{mM}$ diheptanoyl thio-PC was used as a positive control, while $100 \mathrm{M}$ thiotheramide-PC was used as a substrate. The cleavage of the diheptanoyl thio-PC ester produces free thiols, which were detected using DTNB at $420 \mathrm{~nm}$ in a 96-well microplate.

\subsection{Antiaging Assay}

2.8.1. Anti-AGE Formation Activity. The previously reported protocol of Kaewseejan et al. was used to assess the inhibitory potential of vesperlysine AGEs and pentosidine AGE production [39]. 0.5 M glucose solution and 0.1 M PBS containing 0.02 percent $(w / v)$ sodium azide were used to make BSA solution. ZnO-NPs were mixed with a $20 \mathrm{mg} / \mathrm{mL}$ BSA solution. The reaction mixture was kept at $37^{\circ} \mathrm{C}$ for five days in the dark. The fluorescence was estimated and quantified using a Versa Fluor fluorometer from Bio-Rad in France, with a $410 \mathrm{~nm}$ emission wavelength and a $330 \mathrm{~nm}$ excitation wavelength.

2.8.2. Tyrosinase Assay. The tyrosinase test was performed using $5 \mathrm{mM}$ L-DOPA, as previously described by Chai et al. [40]. L-DOPA diphenolase substrate was combined with $10 \mathrm{~mL} \mathrm{ZnO-NPs}$ and sodium phosphate buffer $(50 \mathrm{mM}, \mathrm{pH}$ 6.8). The final volume of the reaction mixture was raised to $200 \mathrm{~mL}$ by adding $0.2 \mathrm{mg} / \mathrm{mL}$ mushroom tyrosinase solution. As a control, extraction solvent in place of the tested $\mathrm{ZnO}$ NPs was employed. At $475 \mathrm{~nm}$, a microplate machine was used to track the reaction activities. The tyrosinase impact on $\mathrm{ZnO}-\mathrm{NPs}$ was reported as \% inhibition compared with matching control.

2.8.3. Elastase Assay. Porcine pancreatic elastase was used in the elastase inhibition test (Sigma-Aldrich). The substrate used in the test was N(AAAVPN). The relative conversion of substrate into $p$-nitroaniline release at $410 \mathrm{~nm}$ was used to quantify the reaction traces using a microplate reader, following the approach of Wittenauer et al. [41].

2.8.4. Hyaluronidase Assay. The potential of $\mathrm{ZnO}-\mathrm{NPs}$ to inhibit hyaluronidase was tested using a technique established by Kolakul et al. [42]. A solution containing 0.03 
percent $(w / v)$ hyaluronic acid and 1.5 units of hyaluronidase was employed as a substrate. The undigested form of hyaluronic acid precipitated in an acid albumin solution (0.1 percent $(w / v)$ BSA). The optical density (OD) at $600 \mathrm{~nm}$ was measured using a spectrophotometer. In contrast to the control, the antihyaluronidase potential was expressed as a percentage inhibition.

2.8.5. Collagenase Assay. The procedure from Wittenauer et al. was used, with a small change in applied concentration [41]. FALGPA obtained from Sigma-Aldrich functioned as a substrate. The reduction in FALGPA absorbance was measured at $335 \mathrm{~nm}$ using a microplate reader over a period of 20 minutes. The trial was conducted in triplicates, and anticollagenase activity was expressed as a percentage inhibition compared to the control.

2.9. Cytotoxicity against the HepG2 Cell Line. HepG2 cells (ATCC HB-8065) were grown in DME medium with $100 \mathrm{~g} / \mathrm{mL}$ streptomycin, $10 \% \mathrm{FCS}, 100 \mathrm{U} / \mathrm{mL}$ penicillin, and $2 \mathrm{mM}$ L-glutamine and incubated at $37^{\circ} \mathrm{C}$ in a humidified $\mathrm{CO}_{2}$ incubator with $5 \%$ humidity. $0.5 \mathrm{mM}$ trypsin/EDTA was used to harvest the cells at 80-90 percent confluence. The cytotoxic potential of ZnO-NPs against HepG2 cells was determined using MTT tetrazolium dye. Preseeded HepG2 cells ( $>90 \%$ viability; $1 \times 10^{4}$ cells/well) were treated for 24 hours in a 96-well plate with $200 \mu \mathrm{g} / \mathrm{mL}$ test samples and incubated in a 5 percent humidified $\mathrm{CO}_{2}$ incubator. After a $24 \mathrm{~h}$ incubation period, $10 \mathrm{~mL}$ of MTT dye $(5 \mathrm{mg} / \mathrm{mL})$ was added to each well and incubated for $3 \mathrm{~h}$. After that, the insoluble formazan was dissolved in a $10 \%$ acidified SDS solution. The cells were then incubated overnight. The plates were examined at $570 \mathrm{~nm}$ using a microplate reader (Platos $\mathrm{R}$ 496, AMP). As a control, we utilized untreated HepG2 cells (NTC) and doxorubicin.

$$
\begin{aligned}
& \text { \%Viability } \\
& =\frac{\text { Absorbance of sample }- \text { Absorbance of sample control }}{\text { Absorbance of NTC }- \text { Absorbance of media }} \times 100 \text {. }
\end{aligned}
$$

Optical density of treated samples and NTC was measured at $570 \mathrm{~nm}$.

\section{Results and Discussion}

3.1. Synthesis and HPLC Analysis of Green ZnO-NPs. Aquilegia pubiflora leaf extract has been employed as a reducing and stabilizing agent in the production of multifunctional $\mathrm{ZnO}-\mathrm{NPs}$ in recent study. The genus Aquilegia is a member of the Ranunculaceae family, which comprises around 60 plant species used for a variety of medicinal purposes across the world, mostly in South Asia. Among the medicinally important phytochemicals identified in these plants are ferulic acid, $\beta$-sitosterol, apigenin, aquilegiolide, magnoflorine, berberine, caffeic acid, $p$-coumaric acid, genkwanin, glochidionolactone A, and resorcylic acid [27, 43]. These phytochemicals, such as phenolics and flavonoids, may have played an important role in the formation of stable nanopar- ticles. HPLC was used to produce and quantify the fundamental phytochemicals responsible for the reduction and effective capping of synthesized NPs. Eight constituents were identified and measured, including four hydroxycinnamic acid derivatives (sinapic acid, ferulic acid, chlorogenic acid, and $p$-coumaric acid) and four flavonoids (orientin, vitexin, isoorientin, and isovitexin). Hydroxycinnamic acids and flavonoids are phenolics that are produced through the shikimic acid pathway and are involved in a range of biological processes in plants $[27,31]$. Orientin and chlorogenic acid both protect plants against stresses and have a wide range of biological activities, including antifungal, anticancer, antidiabetic, antibacterial, antioxidant, anti-inflammatory, and hepatoprotective effects $[44,45]$. According to the findings of earlier studies, flavonoids and hydroxycinnamic acid derivatives can be found on the surface of nanoparticles $[27,32,46]$. These plant active chemicals have a role in ZnO-NP capping. White $\mathrm{ZnO}-\mathrm{NP}$ powder was produced after washing, drying, grinding, and calcination operations. The fine powder was collected and kept as ZnO-NPs in an airtight glass container before being employed for physicochemical and morphological evaluation, as well as biological applications [27].

\subsection{Physicochemical and Morphological Characterization.}

The XRD pattern of synthesized ZnO-NPs showed the presence of pure and crystalline nanoparticles, with high diffraction peaks observed at various stages, i.e., $69.47^{\circ}, 68.23^{\circ}$, $66.83^{\circ}, 62.68^{\circ}, 56.31^{\circ}, 47.39^{\circ}, 36.36^{\circ}, 34.34^{\circ}$, and $36.36^{\circ}$, referring to different Miller indices, respectively (201), (212), (200), (103), (102), (101), (002), and (100) as shown in Figure $1 \mathrm{~S}(\mathrm{~A})$. The indexing of $\mathrm{ZnO}$ with a mean size of $19.58 \mathrm{~nm}$ supports the normal hexagonal wurtzite structure (JCPDF file no. 00-036-1451) [47, 48]. The FTIR spectra of the synthesized nanoparticles were estimated in the spectral range of $400-4000 \mathrm{~cm}^{-1}$ as shown in Figure $1 \mathrm{~S}(\mathrm{~B})$. The main absorption peaks were identified in the range of lower wavenumbers. The broad band observed at $3100 \mathrm{~cm}^{-1}$ corresponds to the $\mathrm{O}-\mathrm{H}$ stretching mode of the hydroxyl group. The highest strength at $1459^{-1}$ in the protein amide connection indicated amine $(-\mathrm{NH})$ vibration stretch. The prominent bands detected at $1028 \mathrm{~cm}^{-1}$ and $1384 \mathrm{~cm}^{-1}$ represented alcohols, phenolic compounds, and C-N stretching vibrations of aromatic amines in biomolecules. $\mathrm{Zn}-\mathrm{O}$ refers to a distinct band that can be seen at $863 \mathrm{~cm}^{-1}$ [49-51]. The surface shape and particle size of greensynthesized $\mathrm{ZnO}-\mathrm{NPs}$ are determined by scanning electron microscopy, as illustrated in Figures 2S(A) and 2S(B). The micrograph showed that, with some degree of aggregation, the particles exhibit a spherical structure. In previous research, such morphologies have also been identified. Furthermore, using the ImageJ program, the average particle size of the nanoparticles was $34.23 \mathrm{~nm}[52,53]$. The dispersion power of $\mathrm{ZnO}-\mathrm{NPs}$ in deionized water at $\mathrm{pH} 2$, $\mathrm{pH} 7$, and $\mathrm{pH} 12$ was investigated. It was noted that even after $24 \mathrm{~h}$ of sonication, $\mathrm{ZnO}-\mathrm{NPs}$ demonstrated excellent dispersion at neutral $\mathrm{pH}$. Moreover, at neutral $\mathrm{pH}$, the dispersion effect was also enhanced by a highly negative zeta potential value [54]. The zeta potential and particle size 
TABLE 1: $\alpha$-Amylase and $\alpha$-glycosidase potential at various concentrations.

\begin{tabular}{lcccccc}
\hline \multirow{2}{*}{ Enzymes } & & \multicolumn{2}{c}{ Concentrations $(\mu \mathrm{g} / \mathrm{mL})$} \\
& + Control & 12.5 & 25 & 50 & 100 & 200 \\
\hline$\alpha$-Amylase & $88.63 \pm 3.79$ & $18.91 \pm 0.73^{* * *}$ & $22.49 \pm 0.54^{* *}$ & $27.19 \pm 0.63^{* *}$ & $28.36 \pm 0.69^{* *}$ & $31 \pm 0.24^{*}$ \\
$\alpha$-Glucosidase & $88.63 \pm 3.79$ & $16.31 \pm 0.44^{* * *}$ & $18.66 \pm 0.59^{* *}$ & $21.43 \pm 1.06^{*}$ & $21.91 \pm 1.19^{*}$ & $22.69 \pm 1.23^{*}$ \\
\hline
\end{tabular}

distribution were investigated using the Malvern Zetasizer, as shown in Figures 3S(A) and 3S(B). The colloidal stability of particles is determined by the zeta potential $|\zeta|$, which is a common estimate of the surface load. Suspensions featuring $|\zeta| 15 \mathrm{mV}$ are normally graded as stable colloids. The calculation also improves the stable dispersion potential of biogenic $\mathrm{ZnO}-\mathrm{NPs}$ at $\mathrm{pH} 7$ in distilled water. The negative surface charge on particles provides particle dispersion stability and prevents aggregation due to the high binding affinity of the extract compounds on metallic ions. In addition, calculations of the size distribution showed the average particle size to be $131 \mathrm{~nm}$. The larger $\mathrm{ZnO}-\mathrm{NPs}$ detected by DLS are due to the technique's bias against measuring larger particles (even aggregate) [54, 55]. Photoluminescence (PL) analysis of engineered nanomaterials is significant because it gives important information on the quality of the synthesized materials. Excitation wavelengths ranging from $500 \mathrm{~nm}$ to $900 \mathrm{~nm}$ were used to measure the PL. Characteristic peaks, referred to as trap state or deep state emission, were found at $510 \mathrm{~nm}, 552 \mathrm{~nm}$, and $690 \mathrm{~nm}$, as shown in Figure $4 \mathrm{~S}(\mathrm{~A})$. There are three possible charge states for oxygen vacancies in $\mathrm{ZnO}$ : neutral, single ionized, and double ionized. While the presence of oxygen is responsible for green oxygen emissions from $\mathrm{ZnO}-\mathrm{NPs}$, the rise in oxygen vacancies is linked to high PL emissions [56, 57]. Figure 4S(B) shows the Raman spectra of biosynthesized nanoparticles, which revealed typical peaks at $435 \mathrm{~cm}^{-1}$ and $572 \mathrm{~cm}^{-1}[27,58]$.

3.3. Antidiabetic Activity. Diabetes mellitus (DM) is a metabolic condition characterized by hyperglycemia that persists. It is caused by a lack of insulin synthesis or a lack of insulin sensitivity in the body's cells [59]. The International Diabetes Federation (IDF) study (2017) estimated that 425 million adults have diabetes, with that number expected to rise to 629 million by 2045 [60]. Lowering postprandial hyperglycemia is one of the important clinical approaches to diabetes care. This can be accomplished by inhibiting two essential digestive tract enzymes that hydrolyze carbohydrates, i.e., alpha-amylase and alpha-glucosidase [59]. Various doses of $\mathrm{ZnO}-\mathrm{NPs}$ ranging from $12.5 \mu \mathrm{g} / \mathrm{mL}$ to $200 \mu \mathrm{g} / \mathrm{mL}$ were tested in the assay for $\alpha$-amylase and $\alpha$-glucosidase inhibition. Our findings suggest that $\mathrm{ZnO}$-NPs have a mild inhibitory effect on $\alpha$-amylase and $\alpha$-glucosidase activity, which is consistent with previous research (Table 1) [61]. At the highest concentration of $200 \mu \mathrm{g} / \mathrm{mL}$, the maximum inhibition of $\alpha$-amylase was determined to be 310.24 , whereas the maximum inhibition of $\alpha$-glucosidase was calculated to be 22.691.23. Overall, both enzymes' \% inhibition increased in a dose-dependent manner; however, $\alpha$-amylase showed considerably greater inhibition as compared to $\alpha$-glycosidase, while considering the comparable inhibitory effect of both enzymes. Hence, ZnO-NPs synthesized from Aquilegia pubiflora have moderate antidiabetic properties; this could be due to the presence of some active compounds that inhibit diabetes-related enzymes.

${ }^{* * *}$ Highly significant, ${ }^{* *}$ slightly significant, and *nonsignificant difference from control at $P<0.05$ by one-way ANOVA in the column. The values represent the mean \pm SD of three replicates.

3.4. Antioxidant Activity. A variety of test methods have been devised and employed due to the relevance of antioxidants in protecting natural and man-made materials. Methods based on inhibited autoxidation, oxygen consumption kinetics, or the formation of hydroperoxides and primary oxidation products are among them. Secondary oxidation products (e.g., carbonyl compounds) were also determined analytically [62]. However, most test methods do not involve substrate autoxidation. For this purpose, we have used four different antioxidant assays to gain a better understanding of test samples' antioxidant potential in terms of secondary oxidation products, primary oxidation products, and oxygen consumption kinetics [63]. Because the radical is stable and does not need to be generated as in other scavenging assays, the DPPH method is the most valid, easy, accurate, sensitive, and costeffective method for evaluating the scavenging activity of antioxidants in fruits, vegetables, juices, extracts, and extract-mediated nanomaterials [62]. The results are very repeatable and comparable to ABTS, TAC, ORAC, and FRAC, as well as other scavenging methods. Another strategy, which considers the antioxidant concentration and reaction time to reach the scavenging reaction plateau, has been found to be superior to other methods (considering only antioxidant concentration) [63].

For these assays, five separate concentrations, i.e., 200, $100,50,25$, and $12.5 \mu \mathrm{g} / \mathrm{mL}$, were used and the results demonstrated that antioxidant potential of the $\mathrm{ZnO}$-NPs was highly significantly upregulated shown in Table 2. Since aqueous extracts of $A$. pubiflora are available in this sample, it may be concluded that some of the phenolic compounds involved in capping of $\mathrm{ZnO}$-NPs can quench the reactive oxygen species by acting as reducing/oxidizing agents. The test material's total antioxidant potential (TAC) is predicated on its conversion from Mo (VI) to Mo (V), and the greenish Mo (V)-phosphate complex had the fastest absorption at $695 \mathrm{~nm}$. TAC assay reveals the quenching ability of the measured material compared to ROS species [64]. At a higher concentration of $200 \mu \mathrm{g} / \mathrm{mL} \mathrm{ZnO}-\mathrm{NP}$ concentration, moderate $(71.66 \pm 1.14)$ TAC activity was observed while at lower concentration of NPs $(12.5 \mu \mathrm{g} / \mathrm{mL})$ TAC activity was further decreased as $26.78 \pm 1.22$. The antioxidant potential of $\mathrm{ZnO}$ - 
TABLe 2: Antioxidant potential of A. pubiflora-synthesized ZnO-NPs.

\begin{tabular}{lccccc}
\hline Conc. $(\mu \mathrm{g} / \mathrm{mL})$ & TAC $(\mu \mathrm{g}$ AAE $/ \mathrm{mg})$ & TRP $(\mu \mathrm{g} \mathrm{AAE} / \mathrm{mg})$ & ABTS $(\mathrm{TEAC})$ & DPPH $(\%$ FRSA $)$ & Ascorbic acid \\
\hline 200 & $71.66 \pm 1.14^{* *}$ & $111.32 \pm 1.24^{* *}$ & $178.45 \pm 2.64^{*}$ & $23.5 \pm 1.38^{* * *}$ & $210.29 \pm 4.72$ \\
100 & $53.71 \pm 1.32^{* *}$ & $86.71 \pm 0.98^{* *}$ & $124.32 \pm 1.99^{*}$ & $18.11 \pm 1.2^{* * *}$ & $186.31 \pm 4.19$ \\
50 & $42.43 \pm 0.84^{* *}$ & $54.23 \pm 0.92^{* *}$ & $92.63 \pm 2.25^{*}$ & $13.32 \pm 1.74^{* * *}$ & $132.20 \pm 4.03$ \\
25 & $31.72 \pm 0.71^{* *}$ & $32.87 \pm 0.95^{* *}$ & $68.54 \pm 2.21^{*}$ & $7.0 \pm 0.97^{* * *}$ & $119.18 \pm 2.83$ \\
12.5 & $26.78 \pm 1.22^{*}$ & $19.23 \pm 1.13^{* *}$ & $45.73 \pm 1.91^{*}$ & $6.37 \pm 1.82^{* * *}$ & $84.71 \pm 2.51$ \\
\hline
\end{tabular}

NPs was further determined by engineered power reduction test (TRP). Redox-possessing agent can neutralize and absorb free radicals by transferring the ion from $\mathrm{Fe}^{+} 3$ to $\mathrm{Fe}^{+} 2$. $\mathrm{ZnO}-\mathrm{NPs}$ with reducing strength are capable to reduce ferrous ions from ferric ions [65]. Reductants have the ability to reduce free radicals by splitting their chains and donating a hydrogen atom, and this reduction capacity is linked to antioxidant capacity [66].

TRP experiment indicated the maximum antioxidant potential $(111.32 \pm 1.24 \mu \mathrm{g}$ AAE $/ \mathrm{mg})$ for the $200 \mu \mathrm{g} / \mathrm{mL}$ $\mathrm{ZnO}-\mathrm{NP}$ tested concentration in terms of ascorbic acid equivalents in antioxidant activities. However, from overall antioxidant assays performed (TRP, TAC, DPPH, and ABTS) using different concentrations of $\mathrm{ZnO}-\mathrm{NPs}$, the highest antioxidant activity was noted for ABTS assay $(178.45 \pm 2.64)$ at $200 \mu \mathrm{g} / \mathrm{mL} \mathrm{ZnO}-\mathrm{NP}$ tested concentration. The reducing strength of the $\mathrm{ZnO}-\mathrm{NPs}$ in the performed assays (TRP, TAC, DPPH, and ABTS) was shown to be gradually decreased with the decrease of tested concentrations of NPs. The highest reduction capacity for TRP assay was revealed at $200 \mu \mathrm{g} / \mathrm{mL} \mathrm{ZnO}-\mathrm{NP}$ concentration as 111.3 $\pm 2.44 \mu \mathrm{g} \mathrm{AAE} / \mathrm{mg}$, and the least reduction potential was noted at $12.5 \mu \mathrm{g} / \mathrm{mL}$ as $19.11 \pm 2.6 \mu \mathrm{g} \mathrm{AAE} / \mathrm{mg}$. Both spectrophotometric approaches, DPPH free radical scavenging and ABTS assays, are based on the quenching of stablecolored DPPH and ABTS radicals, indicating the ability to scavenge of antioxidants [67]. At a concentration of $200 \mu \mathrm{g} / \mathrm{mL}$ ZnO-NPs, medium $(23.5 \pm 2.4) \mathrm{DPPH}$ radical scavenging activity was observed while low radical scavenging potential $(6.37 \pm 1.82)$ was observed at $12.5 \mu \mathrm{g} / \mathrm{mL}$. Similarly, the highest ABTS activity $(178.45 \pm 2.64)$ was recorded at $200 \mu \mathrm{g} / \mathrm{mL} \mathrm{ZnO}-\mathrm{NP}$ concentration and the lowest $(45.73 \pm 1.91)$ at $12.5 \mu \mathrm{g} / \mathrm{mL}$. Some of the antioxidant chemicals involved in the reduction and stabilization of $\mathrm{ZnO}-\mathrm{NPs}$ throughout the manufacturing process could also be responsible for imparting antioxidant capabilities to $\mathrm{ZnO}-\mathrm{NPs}$, according to the findings.

${ }^{* * *}$ Highly significant, ${ }^{* *}$ slightly significant, and *nonsignificant difference from control at $P<0.05$ by one-way ANOVA in the column. Values are mean \pm SD of triplicate.

3.5. In Vitro Anti-Alzheimer's Activity. Alzheimer's disease $(\mathrm{AD})$ is a chronic neurological disease that accounts for $60 \%$ to $80 \%$ of dementia cases worldwide. The condition is characterized by a gradual decline in cognitive functions such as memory, executive and visual spatial functioning, personality, and vocabulary. In the United States alone, one person develops Alzheimer's disease every 65 seconds, which is alarming [68]. Cholinesterase inhibitors are new AD medicines accessible for people with any stage of the disease. For the successful inhibition of cholinesterase enzymes, a variety of synthetic and natural substances have been described. In tissue synapses or neuromuscular junctions, the enzymes catalyze the hydrolysis of acetyl choline (a neurotransmitter) into choline and acetic acid. Nanotechnology, a diverse field, is a potential hotspot for identifying various therapeutic strategies, including drug delivery across the blood-brain barrier in Alzheimer's disease. Efficient disintegration of mature fibrils and remarkable inhibition of the $\beta$-amyloid fibrillation mechanism have been suggested by Terminalia arjuna-dependent gold nanoparticles. In addition, gold nanoparticles have also been reported to be successful in inhibiting cholinesterase enzymes, suggesting that gold nanoparticles are neuroprotective [69]. Trehalose-functionalized gold nanoparticles disintegrate matured fibrils and inhibit protein aggregation [70]. Bacopa monnieri-based platinum nanoparticles commendably eradicate reactive oxygen species which tends to drop the ROS level in Parkinson disorder [71]. Selenium and other metal oxide nanoparticles are also used effectively for $\mathrm{AD}$ on in vivo and in vitro basis [72]. The decrease in acetyl choline levels leads to the development of Alzheimer's disease. The inhibitory reaction of two cholinesterase enzymes, butyrylcholinesterase (BChE) and acetylcholinesterase (AChE), was investigated using different biogenic ZnO-NP concentrations (AChE) [73]. The inhibitory response for both esterases was dose dependent, which was surprising. The most active concentration of $\mathrm{ZnO}-\mathrm{NPs}$ was $200 \mu \mathrm{g} / \mathrm{mL}$, which inhibited AChE by $64.76 \pm 1.69$ and $\mathrm{BChE}$ by $67.49 \pm 0.60$. At $12.5 \mu \mathrm{g} / \mathrm{mL} \mathrm{ZnO}-\mathrm{NP}$ concentration, the inhibitory response was $35.76 \pm 1.01$ for $\mathrm{AChE}$ and $27.51 \pm 0.84$ for $\mathrm{BChE}$, respectively. Furthermore, no significant difference in percent inhibition was recorded against both enzymes at $25 \mu \mathrm{g} / \mathrm{mL}$ and $50 \mu \mathrm{g} / \mathrm{mL}$ concentrations of $\mathrm{ZnO}-\mathrm{NPs}$, with inhibition responses of $38.02 \pm 1.03$ at $25 \mu \mathrm{g} / \mathrm{mL}$ and $40.02 \pm 0.09$ at $50 \mu \mathrm{g} / \mathrm{mL}$ for $\mathrm{AChE}$ and $29.01 \pm 0.94$ at $25 \mu \mathrm{g} / \mathrm{mL}$ and $30.01 \pm 0.08$ at $50 \mu \mathrm{g} / \mathrm{mL}$ for $\mathrm{BChE}$, respectively. Overall, $\mathrm{ZnO}-\mathrm{NPs}$ were found to be highly active against both enzymes as indicated by their IC $_{50}$ values of $102 \mu \mathrm{g} / \mathrm{mL}$ and $125 \mu \mathrm{g} / \mathrm{mL}$ for $\mathrm{AChE}$ and BChE. Overall results exhibited that biosynthesized $\mathrm{ZnO}$ NPs have efficient anti-Alzheimer's activity and as shown by significant $\%$ inhibition at $200 \mu \mathrm{g} / \mathrm{mL}$ concentration, against both enzymes, respective to control as shown in Table 3. The results of the present study exhibited that $A$. pubiflora-mediated $\mathrm{ZnO}-\mathrm{NPs}$ have effective antiAlzheimer's activity when applied in high concentrations, 
TABLE 3: Acetylcholinesterase (AChE) and butyrylcholinesterase (BChE) inhibition by ZnO-NPs at different concentrations.

\begin{tabular}{|c|c|c|c|c|c|}
\hline \multirow{2}{*}{ Enzymes } & \multicolumn{5}{|c|}{ Concentrations $(\mu \mathrm{g} / \mathrm{mL})$} \\
\hline & 12.5 & 25 & 50 & 100 & 200 \\
\hline AChE & $35.76 \pm 1.01^{*}$ & $37.54 \pm 0.54^{* *}$ & $40.89 \pm 0.63^{* *}$ & $52.44 \pm 0.69^{* *}$ & $64.76 \pm 1.69^{*}$ \\
\hline BChE & $27.51 \pm 0.84^{* *}$ & $27.69 \pm 0.59^{* *}$ & $36.81 \pm 1.06^{*}$ & $49.73 \pm 1.19^{* *}$ & $67.49 \pm 0.60^{*}$ \\
\hline+ Control & $52.41 \pm 2.19$ & $58.72 \pm 2.11$ & $62.79 \pm 2.44$ & $81.83 \pm 2.68$ & $86.20 \pm 2.91$ \\
\hline
\end{tabular}

as shown by $>65 \%$ inhibition against both enzymes. A previous study by Khalil et al. (2019) showed inhibition of several metallic NPs against AChE and BChE enzymes. Concentrations of biogenic metal oxide nanoparticles ranging from $1000 \mathrm{mg} / \mathrm{mL}$ to $62.5 \mathrm{mg} / \mathrm{mL}$ were examined. Surprisingly, both enzymes' responses to inhibition were found to be dose dependent. At $1000 \mathrm{mg} / \mathrm{mL}$, biogenic lead oxide ( $\mathrm{PbO}$ ) nanoparticles were one of the most active samples, suppressing cholinesterases by $71 \%$ (AChE) and $67 \%$ (BChE). This was followed by cobalt oxide nanoparticles, which suppressed AChE and BChE by $70 \%$ and $68 \%$, respectively. With $\mathrm{IC}_{50}$ values of $160.81 \mathrm{mg} / \mathrm{mL}$ and $261.67 \mathrm{mg} / \mathrm{mL}$ for AChE and $\mathrm{BChE}$, respectively, biogenic iron oxide nanoparticles were the least effective [73].

***Highly significant, ${ }^{* *}$ slightly significant, and *nonsignificant difference from control at $P<0.05$ by one-way ANOVA in the column. Values are mean \pm SD of triplicate.

3.6. In Vitro Anti-Inflammatory Activity. Inflammation is an automated response exhibited by the body's immune system, against various bacteria, irritants, damaged cells, and adverse stimuli. Anti-inflammatory activities have been documented both in vivo and in vitro for different metallic NPs and for many secondary metabolites. ZnO-NP HPLC analysis shows good capping of flavonoids such as orientin, isoorientin, vitexin, and isovitexin. These flavonoids can exert antiinflammatory stress in numerous ways, such as cyclooxygenase inhibition with often selective activity on COX-1 vs. COX-2, phospholipase A2, and lipoxygenases (enzymes developing eicosanoids), thus reducing the concentration of leukotrienes and prostanoids that plays a main role in developing inflammation [74]. In certain types of inflammatory disorders, existing therapies are currently ineffective to treat and mitigate the progression of the condition or even to eradicate the signs and symptoms of inflammation [75]. For example, we know that NPs have an exceptional capacity to penetrate the microbial membrane, so this issue can be solved by increasing drug penetration into the active site of microbial infection. The aim of recent science for developing NPs is to avoid and manage inflammatory and contaminated sites for identification [76-78]. So, to check the anti-inflammatory potential of $A$. pubiflora-mediated $\mathrm{ZnO}-\mathrm{NPs}$, various in vitro pathways such as COX-1, COX-2, sPLA2, and 15-LOX inhibitions were tested. All the pathways produced the most productive outcomes for the inhibitory activity of all experiments conducted. sPLA2 was found to have the highest inhibitory activity $(32.90 \pm 0.99 \%)$, followed by $15-\mathrm{LOX}$ $(24.57 \pm 0.79 \%), \quad$ COX $-1 \quad(18.41 \pm 0.54 \%), \quad$ and COX -2 $(18.23 \pm 0.57 \%)$, respectively, as shown in Figure 1(a). Overall results described that $A$. pubiflora-mediated $\mathrm{ZnO}-\mathrm{NPs}$ have showed efficient inhibition of two enzymes, sPLA2 and 15-LOX, of inflammatory processes.

3.7. In Vitro Antiaging Activity. This assay comprised a screening of $A$. pubiflora-mediated $\mathrm{ZnO}$-NPs for anti-aging potential. A test sample ( $\mathrm{ZnO}-\mathrm{NPs}$ ) at a fixed concentration of $200 \mu \mathrm{g} / \mathrm{mL}$ was utilized to assess their in vitro potential to inhibit enzymes such as tyrosinase, elastase, collagenase, hyaluronidase, and AGEs. Collagenase, hyaluronidase, and elastase-like enzymes are responsible for the destruction of extracellular matrix components in enzymes. Deep wrinkles, skin tonus, and skin resilience losses are all caused by these enzymes [79-81]. Tyrosinase disorders are caused by the phenomenon of aging and are the main causative agents of malignant melanoma and freckles or melasma, such as pigment disorders [82]. Advanced glycation end products (AGEs) have been linked to aging and age-related disorders as a result of oxidative stress [83, 84]. Certain compounds that can deter these enzymatic processes or pathways are desirable and useful in cosmetic industries. According to several studies, SIRT-1 (a class III deacetylase) and radical aging theory have emerged as potent survival and oxidative stress management agents $[85,86]$. In our recent study, $\mathrm{ZnO}-\mathrm{NPs}$ produced with some phytochemicals have shown that these NPs are capable of being used as antiaging agents. Significant inhibitory activities of ZnO-NPs against pentosidine AGEs (up to $44.63 \pm 1.26 \%$ ) have been observed, followed by vesperlysine AGEs (up to $37.13 \pm 1.99 \%$ ). For collagenase $(17.83 \pm 0.81 \%)$ and tyrosinase $(14.56 \pm 0.89)$, ZnO-NPs had intermediate inhibitory effect. The lowest observed pronounced inhibitory effects observed for elastase and hyaluronidase were $7.51 \pm 0.31$ and $8.73 \pm 0.37$, respectively, shown in Figure 1(b). It has been explained from the above findings that $\mathrm{ZnO}-\mathrm{NPs}$ have a good inhibitory capacity against two enzymes, AGEs of pentosidine and vesperlysine. Previous research has shown that $\mathrm{ZnO}$ may absorb UV radiation and protect the skin from additional damage, making it a potential antiaging agent. When coupled with $\mathrm{TiO}_{2}, \mathrm{ZnO}-$ NPs and green tea polyphenols show synergistic photoprotective effects on the skin, significantly reducing erythema [87]. $\mathrm{ZnO}$ is claimed to be an antiaging element in cosmetics and sunscreens since it is an active UVA/UVB-reflecting sunscreen ingredient that provides UVB protection of $75 \%$. The anti-aging potential of $\mathrm{ZnO}-\mathrm{NPs}$ and $\mathrm{TiO}_{2}-\mathrm{NPs}$ in sunscreens is owing to their capacity to form complexes with proteins and cause the creation of free radicals, hence triggering ROS and inhibiting many proteins involved in aging [88].

3.8. Anticancer Activity against the HepG2 Cell Line. Plantderived compounds are a promising treatment option for 


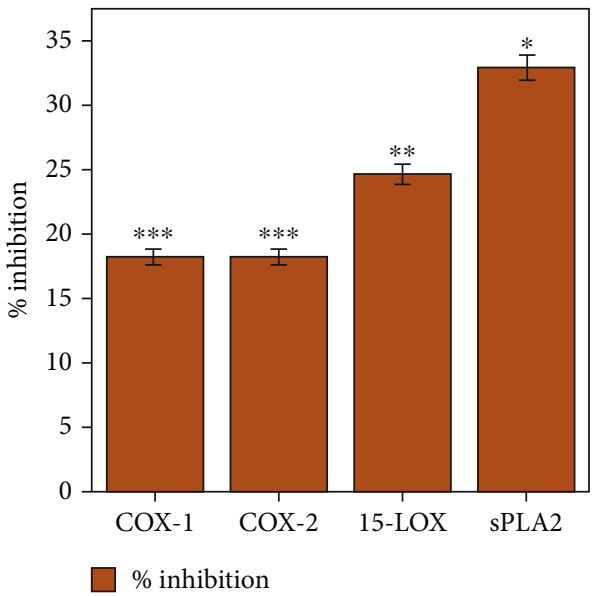

(a)

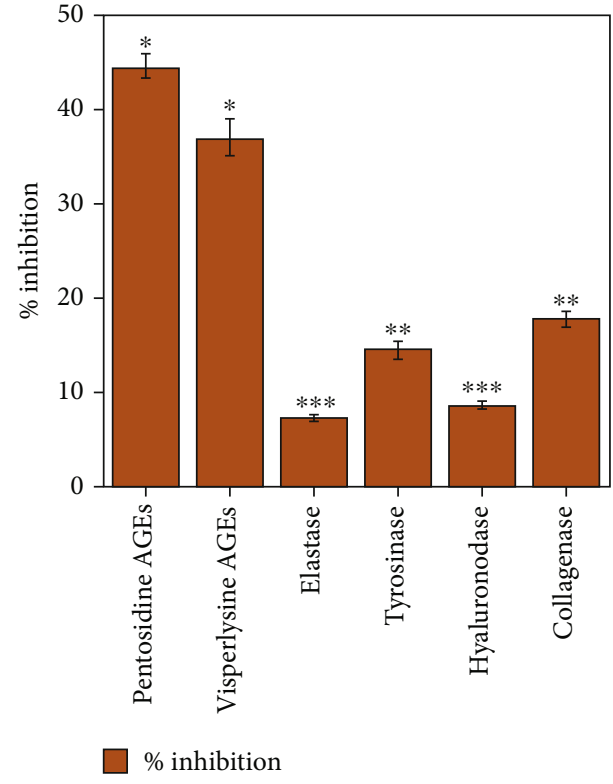

(b)

Figure 1: (a) Anti-inflammatory potential of synthesized ZnO-NPs with respect to their control value (68.39 \pm 3.17 ). (b) Antiaging potential of $\mathrm{ZnO}-\mathrm{NPs}$ with respect to their control value $(74.83 \pm 3.92)$. ${ }^{* * *}$ Highly significant, ${ }^{* *}$ slightly significant, and ${ }^{*}$ nonsignificant difference from control at $P<0.05$ by one-way ANOVA in the column. Values are mean $\pm \mathrm{SD}$ of triplicate.

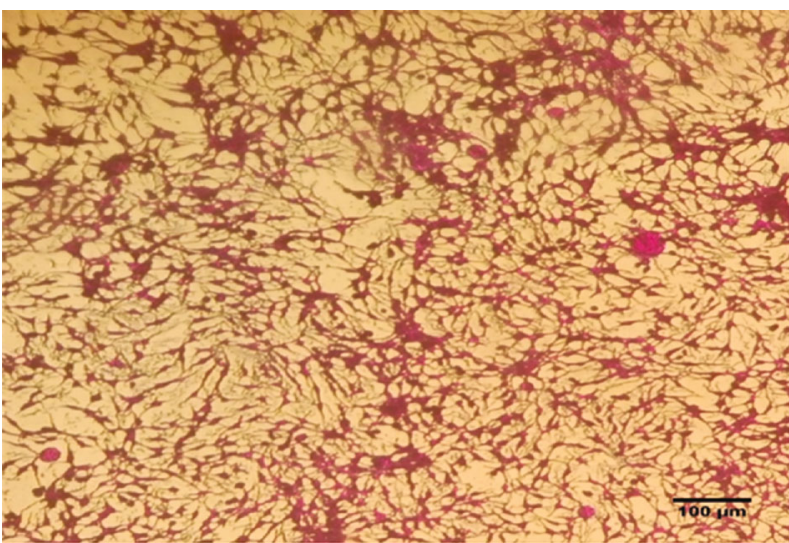

(a)

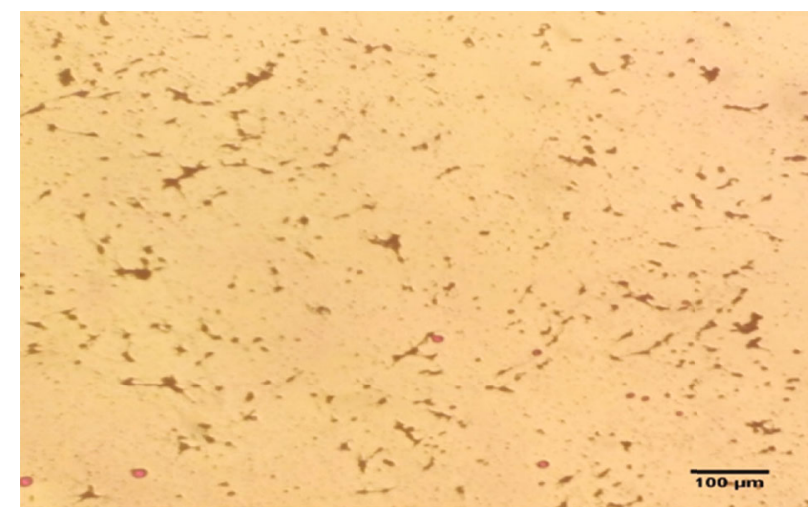

(b)

Figure 2: (a) Characteristic pictures of nontreated cells. (b) ZnO-NP-treated cells.

hepatocellular carcinoma [89]. In our research, FTIR and HPLC analyses reported the presence of alcohols, phenolic groups, and $\mathrm{C}-\mathrm{N}$ stretching vibrations of aromatic amines of biomolecules, on the surface of synthesized $\mathrm{ZnO}-\mathrm{NPs}$; these groups are considered physiologically significant towards treatment of various pathogenic diseases including cancer [90]. A scientific hotspot for cancer therapy is provided by the toxic nature of NPs, having effective anticancer potential $[55,90]$. In this study, the cytotoxicity of ZnO-NPs against human hepatocytes (HepG2 cell line) has been examined. HepG2 cells showed reduced cell viability of $23.68 \pm 2.1 \%$ after $24 \mathrm{~h} \mathrm{ZnO}$-NP treatment, as compared to respective controls as shown in Figure 2. Moreover, the phase-contrast microscopic images of HepG2 cells treated with $\mathrm{ZnO}-\mathrm{NPs}$ showed prominent apoptosis of cells after for $24 \mathrm{~h}$ treatment. These results indicated the highly toxic effect of ZnO-NPs against human hepatocytes, as shown in Table 4. The three primary mechanisms responsible for the cytotoxic effect of $\mathrm{ZnO}-\mathrm{NPs}$ include the breakdown of $\mathrm{ZnO}-\mathrm{NPs}$ into $\mathrm{Zn}^{+} 2$, reactive oxygen species (ROS) formation, and DNA damage [91-93]. Moreover, physical properties such as size, surface chemistry, and dose dictate the overall uptake, elimination, and antitumor properties of the ZnO-NPs [93]. Various studies have showed the anticancer and antiproliferative effect of $\mathrm{ZnO}-\mathrm{NPs}$, via upregulating the tumor suppressor genes and apoptotic genes, downregulating the antiapoptotic genes, inducing DNA fragmentation, ROS production, and caspase- 3 enzyme in HepG2 cells [94-96]. Our results are also consistent with these previously published studies regarding anticancer potential of 
TABLE 4: Anticancer potential of $\mathrm{ZnO}-\mathrm{NPs}$ and plant extract toward the HepG2 cell line.

\begin{tabular}{lcc}
\hline Test sample & \% inhibition & \% viability \\
\hline ZnO-NPs & $76.32 \pm 1.69$ & $23.68 \pm 2.1$ \\
NTC & $100 \pm 2.27$ & 0.00 \\
Doxorubicin & $97.35 \pm 2.84$ & 2.65 \\
Aquilegia pubiflora extract & $24.52 \pm 0.49$ & $75.48 \pm 1.81$ \\
\hline
\end{tabular}

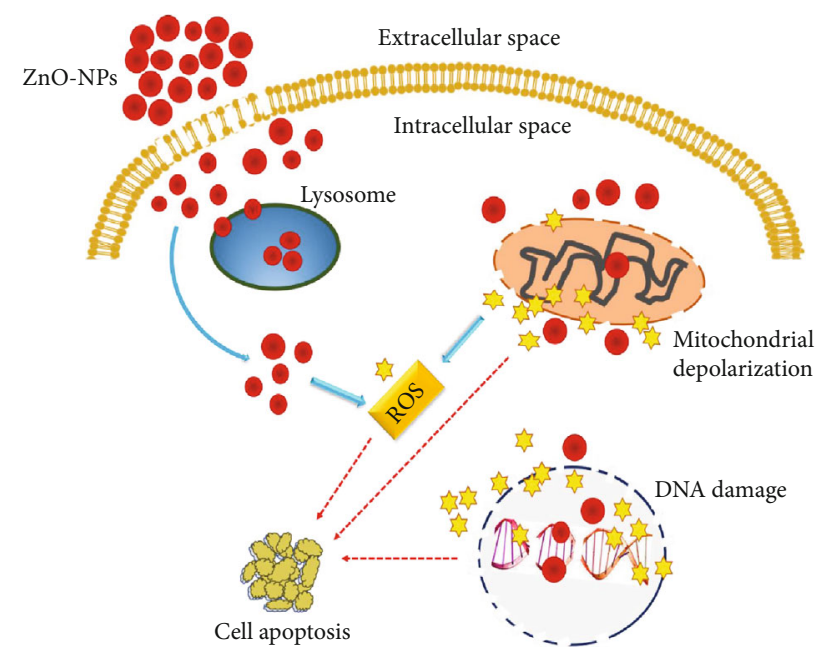

Figure 3: The proposed mechanism of ZnO-NP-mediated cytotoxicity in cancerous cell. NP accumulation and dissolution on the plasma membrane further lead toward lysosome and exert oxidative stress causing generation of ROS. Active ROS causes mitochondrial depolarization and DNA damages finally resulting in cell apoptosis.

Au-NPs against HepG2 cells. Plant-derived Au-NPs typically cause cellular death by causing reactive oxygen species (ROS). ROS disrupts signal transduction pathways while also increasing cellular death $[97,98]$. The $\mathrm{CeO}_{2}-\mathrm{NP}$ antiproliferative activities were also shown to successfully reduce the viability of the HepG2 cell line, with inhibition of $26.78 \%$. The positive control doxorubicin and the negative control DMSO inhibited the HepG2 cells by $94.24 \%$ and $4.24 \%$, respectively, as compared to the $\mathrm{CeO}_{2}-\mathrm{NPs}$ [46]. Hence, the marked anti-tumor activity against HepG2 cells showed an exciting potential of biosynthesized $\mathrm{ZnO}-$ NPs as promising anti-cancer agents. Figure 3 shows the proposed mechanism of $\mathrm{ZnO}-\mathrm{NP}$-mediated cytotoxicity in cancerous cell; when $\mathrm{ZnO}-\mathrm{NPs}$ get entry into the cancerous cell, they produced ROS species, disturbed mitochondrial membrane depolarization, and damaged DNA; all these events eventually leads to apoptosis or death of cancer cell.

Values are mean \pm SD of triplicate.

\section{Conclusion}

This research work is the ongoing portion of the previously biosynthesized ZnO-NPs using aqueous extract of Aquilegia pubiflora, a well-known plant for its medicinal importance. The crystalline structure of the synthesized NPs has been confirmed by XRD analysis. The presence of phytochemicals in converting metallic ions to nanoparticles was investigated by FTIR and HPLC testing. SEM and Raman spectra determined morphology and vibrational modes, while apparent charge and steadiness were determined by DLS. The produced $\mathrm{ZnO}$-NPs have shown good antioxidant and antiAlzheimer capabilities. ZnO-NPs have also revealed a moderate inhibitory ability against alpha-amylase and alpha-glucosidase enzymes. Biosynthesized ZnO-NPs have shown an effective anti-Alzheimer's activity at a higher concentration and showed $>65 \%$ inhibition against both AChE and BChE enzymes. It has been observed that biogenic ZnO-NPs are highly toxic to HepG2 cell lines as indicated by reduced cell viability of the HepG2 cell line after contact to $\mathrm{ZnO}$-NPs. Moreover, $\mathrm{ZnO}-\mathrm{NPs}$ have a good anti-aging property as demonstrated by their inhibitory capacity against two enzymes, AGEs of pentosidine and vesperlysine. Furthermore, A. pubiflora-mediated ZnO-NPs have showed efficient anti-inflammatory capacity as depicted by inhibition of sPLA2 and 15-LOX enzymes responsible for inducing inflammation. Our results concluded that the abovementioned $\mathrm{ZnO}-\mathrm{NPs}$ could be considered for application in cosmetics, owing to their good anti-aging effect, and in treatment of various diseases including cancer, diabetes, Alzheimer's, and other inflammatory diseases, owing to their strong anti-cancer potential and efficient antioxidant properties. To explore its biomedical capabilities at both in vitro and in vivo levels, further research on $\mathrm{ZnO}-\mathrm{NPs}$ is required.

\section{Data Availability}

The datasets used and analyzed during the current research work is available from the corresponding author on reasonable request.

\section{Conflicts of Interest}

All authors declare no competing interests.

\section{Authors' Contributions}

HJ conceptualized, designed, and performed the experiments. HJ wrote the manuscript. MS, AA, and SF provided reagents and analytical tools. $\mathrm{AK}, \mathrm{MR}$, and $\mathrm{SD}$ analyzed the data. $\mathrm{CH}$ and BHA supervised the research work. All authors read and approved the manuscript.

\section{Supplementary Materials}

We have provided supplementary material in a separate file. That file includes Figures 1S, 2S, 3S, and 4S as supplementary figures cited from our previous published article. (Supplementary Materials)

\section{References}

[1] C. Huang, A. Notten, and N. Rasters, "Nanoscience and technology publications and patents: a review of social science studies and search strategies," The Journal of Technology Transfer, vol. 36, no. 2, pp. 145-172, 2011. 
[2] K. N. Thakkar, S. S. Mhatre, and R. Y. Parikh, "Biological synthesis of metallic nanoparticles," Nanomedicine: Nanotechnology, Biology and Medicine, vol. 6, no. 2, pp. 257-262, 2010.

[3] A. Fouda, G. Abdel-Maksoud, M. A. Abdel-Rahman, S. S. Salem, S. E. D. Hassan, and M. A. H. el-Sadany, "Eco-friendly approach utilizing green synthesized nanoparticles for paper conservation against microbes involved in biodeterioration of archaeological manuscript," International Biodeterioration \& Biodegradation, vol. 142, pp. 160-169, 2019.

[4] S. M. Alsharif, S. S. Salem, M. A. Abdel-Rahman et al., "Multifunctional properties of spherical silver nanoparticles fabricated by different microbial taxa," Heliyon, vol. 6, no. 5, article e03943, 2020.

[5] M. S. Aref and S. S. Salem, "Bio-callus synthesis of silver nanoparticles, characterization, and antibacterial activities via _Cinnamomum camphora_callus culture," Biocatalysis and Agricultural Biotechnology, vol. 27, article 101689, 2020.

[6] V. Kumar and S. K. Yadav, "Plant-mediated synthesis of silver and gold nanoparticles and their applications," Journal of Chemical Technology \& Biotechnology, vol. 84, no. 2, pp. 151-157, 2009.

[7] S. Faisal, H. Jan, S. A. Shah et al., "Green synthesis of zinc oxide $(\mathrm{ZnO})$ nanoparticles using aqueous fruit extracts ofMyristica fragrans: their characterizations and biological and environmental applications," ACS Omega, vol. 6, no. 14, pp. 97099722, 2021.

[8] M. Herlekar, S. Barve, and R. Kumar, "Plant-mediated green synthesis of iron nanoparticles," Journal of Nanoparticles, vol. 2014, 9 pages, 2014.

[9] F. Simonis and S. Schilthuizen, Nanotechnology; Innovation Opportunities for Tomorrow's Defence, Report TNO Science \& Industry Future Technology Center, the Netherlands, 2006.

[10] S. S. Salem, E. F. el-Belely, G. Niedbała et al., "Bactericidal and in-vitro cytotoxic efficacy of silver nanoparticles (Ag-NPs) fabricated by endophytic actinomycetes and their use as coating for the textile fabrics," Nanomaterials, vol. 10, no. 10, p. 2082, 2020.

[11] A. Waris, M. Din, A. Ali et al., "A comprehensive review of green synthesis of copper oxide nanoparticles and their diverse biomedical applications," Inorganic Chemistry Communications, vol. 123, article 108369, 2021.

[12] H. Kumar, K. Bhardwaj, K. Kuča et al., "Flower-based green synthesis of metallic nanoparticles: applications beyond fragrance," Nanomaterials, vol. 10, no. 4, p. 766, 2020.

[13] G. M. F. Calixto, J. Bernegossi, L. de Freitas, C. Fontana, and M. Chorilli, "Nanotechnology-based drug delivery systems for photodynamic therapy of cancer: a review," Molecules, vol. 21 , no. 3 , p. $342,2016$.

[14] L. Al-Naamani, S. Dobretsov, and J. Dutta, "Chitosan-zinc oxide nanoparticle composite coating for active food packaging applications," Innovative Food Science \& Emerging Technologies, vol. 38, pp. 231-237, 2016.

[15] B. R. Sankapal, H. B. Gajare, S. S. Karade, R. R. Salunkhe, and D. P. Dubal, "Zinc oxide encapsulated carbon nanotube thin films for energy storage applications," Electrochimica Acta, vol. 192, pp. 377-384, 2016.

[16] R. Kumar, O. al-Dossary, G. Kumar, and A. Umar, "Zinc oxide nanostructures for $\mathrm{NO}_{2}$ gas-sensor applications: a review," Nano-Micro Letters, vol. 7, no. 2, pp. 97-120, 2015.

[17] P. K. Mishra, H. Mishra, A. Ekielski, S. Talegaonkar, and B. Vaidya, "Zinc oxide nanoparticles: a promising nanomater- ial for biomedical applications," Drug Discovery Today, vol. 22, no. 12, pp. 1825-1834, 2017.

[18] M. D. Newman, M. Stotland, and J. I. Ellis, "The safety of nanosized particles in titanium dioxide- and zinc oxidebased sunscreens," Journal of the American Academy of Dermatology, vol. 61, no. 4, pp. 685-692, 2009.

[19] M. Abedini, F. Shariatmadari, M. A. Karimi Torshizi, and H. Ahmadi, "Effects of zinc oxide nanoparticles on the egg quality, immune response, zinc retention, and blood parameters of laying hens in the late phase of production," Journal of Animal Physiology and Animal Nutrition, vol. 102, no. 3, pp. 736-745, 2018.

[20] H. Agarwal, S. Venkat Kumar, and S. Rajeshkumar, "A review on green synthesis of zinc oxide nanoparticles - An ecofriendly approach," Resource-Efficient Technologies, vol. 3, no. 4, pp. 406-413, 2017.

[21] M. Heinlaan, A. Ivask, I. Blinova, H. C. Dubourguier, and A. Kahru, "Toxicity of nanosized and bulk $\mathrm{ZnO}, \mathrm{CuO}$ and $\mathrm{TiO}_{2}$ to bacteria _Vibrio fischeri and crustaceans Daphnia magna and Thamnocephalus platyurus_," Chemosphere, vol. 71, no. 7, pp. 1308-1316, 2008.

[22] U. Dhar and S. Samant, "Endemic plant diversity in the Indian Himalaya I. Ranunculaceae and Paeoniaceae," Journal of Biogeography, vol. 20, no. 6, pp. 659-668, 1993.

[23] A. Hazrat, M. O. Nisar, J. Shah, and S. H. Ahmad, "Ethnobotanical study of some elite plants belonging to Dir, Kohistan valley, Khyber Pukhtunkhwa, Pakistan," Pakistan Journal of Botany, vol. 43, no. 2, pp. 787-795, 2011.

[24] N. Aziz, M. N. Khan, F. Ul Haq et al., "Erythroid induction activity of_Aquilegia fragrans_and_Aquilegia pubiflora_and identification of compounds using liquid chromatographytandem mass spectrometry," Journal of King Saud UniversityScience, vol. 33, no. 1, article 101227, 2021.

[25] H. Jan, H. Usman, M. Shah et al., "Phytochemical analysis and versatile In Vitro evaluation of antimicrobial, cytotoxic and enzyme inhibition potential of different extracts of traditionally used Aquilegia pubiflora Wall. Ex Royle," BMC Complementary Medicine and Therapies, vol. 21, no. 1, article 165, 2021.

[26] S. Faisal, Abdullah, H. Jan et al., "Bio-catalytic activity of novel Mentha arvensis intervened biocompatible magnesium oxide nanomaterials," Catalysts, vol. 11, no. 7, p. 780, 2021.

[27] H. Jan, M. Shah, H. Usman et al., "Biogenic synthesis and characterization of antimicrobial and anti-parasitic zinc oxide $(\mathrm{ZnO})$ nanoparticles using aqueous extracts of the Himalayan columbine (Aquilegia pubiflora)," Frontiers in Materials, vol. 7, p. 249, 2020.

[28] F. Thema, E. Manikandan, M. S. Dhlamini, and M. Maaza, "Green synthesis of $\mathrm{ZnO}$ nanoparticles via Agathosma betulina natural extract," Materials Letters, vol. 161, pp. 124-127, 2015.

[29] T. Zohra, M. Ovais, A. T. Khalil, M. Qasim, M. Ayaz, and Z. K. Shinwari, "Extraction optimization, total phenolic, flavonoid contents, HPLC-DAD analysis and diverse pharmacological evaluations ofDysphania ambrosioides(L.) Mosyakin \& Clemants," Natural Product Research, vol. 33, no. 1, pp. 136-142, 2019.

[30] R. G. Saratale, H. S. Shin, G. Kumar, G. Benelli, D. S. Kim, and G. D. Saratale, "Exploiting antidiabetic activity of silver nanoparticles synthesized usingPunica granatumleaves and anticancer potential against human liver cancer cells (HepG2)," 
Artificial Cells, Nanomedicine, and Biotechnology, vol. 46, no. 1, pp. 211-222, 2018.

[31] H. Usman, M. A. Ullah, H. Jan et al., "Interactive effects of wide-spectrum monochromatic lights on phytochemical production, antioxidant and biological activities of Solanum xanthocarpum callus cultures," Molecules, vol. 25, no. 9, p. 2201, 2020.

[32] M. Shah, S. Nawaz, H. Jan et al., "Synthesis of bio-mediated silver nanoparticles from Silybum marianum and their biological and clinical activities," Materials Science and Engineering: C, vol. 112, article 110889, 2020.

[33] S. Nazir, H. Jan, D. Tungmunnithum et al., "Callus culture of Thai basil is an effective biological system for the production of antioxidants," Molecules, vol. 25, no. 20, p. 4859, 2020.

[34] M. Ahmed, M. Adil, I. U. Haq, M. K. Tipu, M. Qasim, and B. Gul, "RP-HPLC-based phytochemical analysis and diverse pharmacological evaluation ofQuercus floribundaLindl. ex A. Camus nuts extracts," Natural Product Research, vol. 35, no. 13, pp. 2257-2262, 2021.

[35] M. Shah, H. Jan, S. Drouet et al., "Chitosan elicitation impacts flavonolignan biosynthesis in Silybum marianum (L.) Gaertn cell suspension and enhances antioxidant and antiinflammatory activities of cell extracts," Molecules, vol. 26, no. 4, p. 791, 2021.

[36] S. Faisal, M. A. Khan, H. Jan et al., "Edible mushroom (Flammulina velutipes) as biosource for silver nanoparticles: from synthesis to diverse biomedical and environmental applications," Nanotechnology, vol. 32, no. 6, article 065101, 2021.

[37] G. L. Ellman, K. D. Courtney, V. Andres jr., and R. M. Featherstone, "A new and rapid colorimetric determination of acetylcholinesterase activity," Biochemical Pharmacology, vol. 7, no. 2, pp. 88-95, 1961.

[38] M. Imran, H. Jan, S. Faisal et al., "In vitro examination of antiparasitic, anti-Alzheimer, insecticidal and cytotoxic potential of Ajuga bracteosa Wallich leaves extracts," Saudi Journal of Biological Sciences, vol. 28, no. 5, pp. 3031-3036, 2021.

[39] N. Kaewseejan and S. Siriamornpun, "Bioactive components and properties of ethanolic extract and its fractions from Gynura procumbens leaves," Industrial Crops and Products, vol. 74, pp. 271-278, 2015.

[40] W.-M. Chai, Q. Huang, M. Z. Lin et al., "Condensed tannins from longan bark as inhibitor of tyrosinase: structure, activity, and mechanism," Journal of Agricultural and Food Chemistry, vol. 66, no. 4, pp. 908-917, 2018.

[41] J. Wittenauer, S. Mäckle, D. Sußmann, U. Schweiggert-Weisz, and R. Carle, "Inhibitory effects of polyphenols from grape pomace extract on collagenase and elastase activity," Fitoterapia, vol. 101, pp. 179-187, 2015.

[42] P. Kolakul and B. Sripanidkulchai, "Phytochemicals and antiaging potentials of the extracts from Lagerstroemia speciosa and Lagerstroemia floribunda," Industrial Crops and Products, vol. 109, pp. 707-716, 2017.

[43] S. Mushtaq, M. A. Aga, P. H. Qazi et al., "Isolation, characterization and HPLC quantification of compounds from Aquilegia fragrans Benth: Their in vitro antibacterial activities against bovine mastitis pathogens," Journal of Ethnopharmacology, vol. 178, pp. 9-12, 2016.

[44] M. Naveed, V. Hejazi, M. Abbas et al., "Chlorogenic acid (CGA): a pharmacological review and call for further research," Biomedicine \& Pharmacotherapy, vol. 97, pp. 6774, 2018.
[45] K. Y. Lam, A. P. K. Ling, R. Y. Koh, Y. P. Wong, and Y. H. Say, "A review on medicinal properties of orientin," Advances in Pharmacological Sciences, vol. 2016, 9 pages, 2016.

[46] H. Jan, M. A. Khan, H. Usman et al., “TheAquilegia pubiflora(Himalayan columbine) mediated synthesis of nanoceria for diverse biomedical applications," RSC Advances, vol. 10, no. 33, pp. 19219-19231, 2020.

[47] N. Matinise, X. G. Fuku, K. Kaviyarasu, N. Mayedwa, and M. Maaza, "ZnO nanoparticles via Moringa oleifera green synthesis: Physical properties \& mechanism of formation," Applied Surface Science, vol. 406, pp. 339-347, 2017.

[48] S. Vijayakumar, B. Vaseeharan, B. Malaikozhundan, and M. Shobiya, "Laurus nobilis leaf extract mediated green synthesis of $\mathrm{ZnO}$ nanoparticles: Characterization and biomedical applications," Biomedicine \& Pharmacotherapy, vol. 84, pp. 1213-1222, 2016.

[49] G. Sangeetha, S. Rajeshwari, and R. Venckatesh, "Green synthesis of zinc oxide nanoparticles by aloe barbadensis miller leaf extract: Structure and optical properties," Materials Research Bulletin, vol. 46, no. 12, pp. 2560-2566, 2011.

[50] J. Huang, Q. Li, D. Sun et al., "Biosynthesis of silver and gold nanoparticles by novel sundried Cinnamomum camphora leaf," Nanotechnology, vol. 18, no. 10, article 105104, 2007.

[51] U. Vijayalakshmi, M. Chellappa, U. Anjaneyulu, G. Manivasagam, and S. Sethu, "Influence of coating parameter and sintering atmosphere on the corrosion resistance behavior of electrophoretically deposited composite coatings," Materials and Manufacturing Processes, vol. 31, no. 1, pp. 95-106, 2016.

[52] S. A. Khan, F. Noreen, S. Kanwal, A. Iqbal, and G. Hussain, "Green synthesis of $\mathrm{ZnO}$ and $\mathrm{Cu}$-doped $\mathrm{ZnO}$ nanoparticles from leaf extracts of Abutilon indicum, Clerodendrum infortunatum, Clerodendrum inerme and investigation of their biological and photocatalytic activities," Materials Science and Engineering: C, vol. 82, pp. 46-59, 2018.

[53] D. Suresh, P. C. Nethravathi, Udayabhanu, H. Rajanaika, H. Nagabhushana, and S. C. Sharma, "Green synthesis of multifunctional zinc oxide ( $\mathrm{ZnO}$ ) nanoparticles using Cassia fistula plant extract and their photodegradative, antioxidant and antibacterial activities," Materials Science in Semiconductor Processing, vol. 31, pp. 446-454, 2015.

[54] R. H. Fang, A. V. Kroll, W. Gao, and L. Zhang, "Cell membrane coating nanotechnology," Advanced Materials, vol. 30, no. 23, article 1706759, 2018.

[55] K. Vimala, S. Sundarraj, M. Paulpandi, S. Vengatesan, and S. Kannan, "Green synthesized doxorubicin loaded zinc oxide nanoparticles regulates the Bax and Bcl-2 expression in breast and colon carcinoma," Process Biochemistry, vol. 49, no. 1, pp. 160-172, 2014.

[56] D. Raoufi, "Synthesis and microstructural properties of $\mathrm{ZnO}$ nanoparticles prepared by precipitation method," Renewable Energy, vol. 50, pp. 932-937, 2013.

[57] P. Uthirakumar and C.-H. Hong, "Effect of annealing temperature and $\mathrm{pH}$ on morphology and optical property of highly dispersible $\mathrm{ZnO}$ nanoparticles," Materials Characterization, vol. 60, no. 11, pp. 1305-1310, 2009.

[58] A. Diallo, B. D. Ngom, E. Park, and M. Maaza, "Green synthesis of $\mathrm{ZnO}$ nanoparticles by Aspalathus linearis: Structural \& optical properties," Journal of Alloys and Compounds, vol. 646, pp. 425-430, 2015.

[59] S. S. Nair, V. Kavrekar, and A. Mishra, "In vitro studies on alpha amylase and alpha glucosidase inhibitory activities of 
selected plant extracts," European Journal of Experimental Biology, vol. 3, no. 1, pp. 128-132, 2013.

[60] S. B. Aynalem and A. J. Zeleke, "Prevalence of diabetes mellitus and its risk factors among individuals aged 15 years and above in Mizan-Aman town, Southwest Ethiopia, 2016: a cross sectional study," International Journal of Endocrinology, vol. 2018, 7 pages, 2018.

[61] A. Ali, S. Ambreen, R. Javed, S. Tabassum, I. ul Haq, and M. Zia, " $\mathrm{ZnO}$ nanostructure fabrication in different solvents transforms physio- chemical, biological and photodegradable properties," Materials Science and Engineering: C, vol. 74, pp. 137-145, 2017.

[62] R. Amorati and L. Valgimigli, "Advantages and limitations of common testing methods for antioxidants," Free Radical Research, vol. 49, no. 5, pp. 633-649, 2015.

[63] S. Singh and R. Singh, "In VitroMethods of assay of antioxidants: an overview," Food Reviews International, vol. 24, no. 4, pp. 392-415, 2008.

[64] S. Saleem, L. Jafri, I. . Haq et al., "Plants Fagonia cretica L. and Hedera nepalensis $\mathrm{K}$. Koch contain natural compounds with potent dipeptidyl peptidase-4 (DPP-4) inhibitory activity," Journal of Ethnopharmacology, vol. 156, pp. 26-32, 2014.

[65] M.-Y. Shon, T.-H. Kim, and N.-J. Sung, “Antioxidants and free radical scavenging activity of Phellinus baumii (Phellinus of Hymenochaetaceae) extracts," Food Chemistry, vol. 82, no. 4, pp. 593-597, 2003.

[66] L. Moreira, L. G. Dias, J. A. Pereira, and L. Estevinho, “Antioxidant properties, total phenols and pollen analysis of propolis samples from Portugal," Food and Chemical Toxicology, vol. 46, no. 11, pp. 3482-3485, 2008.

[67] M. Zia-Ul-Haq, S. A. Shahid, S. Ahmad, M. Qayum, and I. Khan, "Antioxidant potential of various parts of Ferula assafoetida L," Journal of Medicinal Plants Research, vol. 6, no. 16, pp. 3254-3258, 2012.

[68] J. Weller and A. Budson, "Current understanding of Alzheimer's disease diagnosis and treatment," F1000Research, vol. 7, article 1161, 2018.

[69] N. Suganthy, V. Sri Ramkumar, A. Pugazhendhi, G. Benelli, and G. Archunan, "Biogenic synthesis of gold nanoparticles from Terminalia arjuna bark extract: assessment of safety aspects and neuroprotective potential via antioxidant, anticholinesterase, and antiamyloidogenic effects," Environmental Science and Pollution Research, vol. 25, no. 11, pp. 10418-10433, 2018.

[70] S. Mandal, K. Debnath, N. R. Jana, and N. R. Jana, “Trehalosefunctionalized gold nanoparticle for inhibiting intracellular protein aggregation," Langmuir, vol. 33, no. 49, pp. 1399614003, 2017.

[71] J. Nellore, C. Pauline, and K. Amarnath, "Bacopa monnieri Phytochemicals Mediated Synthesis of Platinum Nanoparticles and Its Neurorescue Effect on 1-Methyl 4-Phenyl 1,2,3,6 Tetrahydropyridine-Induced Experimental Parkinsonism in Zebrafish," Journal of Neurodegenerative Diseases, vol. 2013, Article ID 972391, 8 pages, 2013.

[72] M. Nazıroğlu, S. Muhamad, and L. Pecze, "Nanoparticles as potential clinical therapeutic agents in Alzheimer's disease: focus on selenium nanoparticles," Expert Review of Clinical Pharmacology, vol. 10, no. 7, pp. 773-782, 2017.

[73] A. T. Khalil, M. Ayaz, M. Ovais et al., "In vitro cholinesterase enzymes inhibitory potential and in silico molecular docking studies of biogenic metal oxides nanoparticles," Inorganic and Nano-Metal Chemistry, vol. 48, no. 9, pp. 441-448, 2018.

[74] P. Rathee, H. Chaudhary, S. Rathee, D. Rathee, V. Kumar, and K. Kohli, "Mechanism of action of flavonoids as antiinflammatory agents: a review," Inflammation \& AllergyDrug Targets, vol. 8, no. 3, pp. 229-235, 2009.

[75] H. E. Gendelman, V. Anantharam, T. Bronich et al., "Nanoneuromedicines for degenerative, inflammatory, and infectious nervous system diseases," Nanomedicine: Nanotechnology, Biology and Medicine, vol. 11, no. 3, pp. 751-767, 2015.

[76] K. Blecher, A. Nasir, and A. Friedman, "The growing role of nanotechnology in combating infectious disease," Virulence, vol. 2, no. 5, pp. 395-401, 2011.

[77] V. Wagner, A. Dullaart, A. K. Bock, and A. Zweck, "The emerging nanomedicine landscape," Nature Biotechnology, vol. 24, no. 10, pp. 1211-1217, 2006.

[78] J. McMillan, E. Batrakova, and H. E. Gendelman, Cell delivery of therapeutic nanoparticles, in Progress in molecular biology and translational science, Elsevier, 2011.

[79] D. O. Coricovac, C. O. Soica, D. A. Muntean, R. A. Popovici, C. A. Dehelean, and E. L. Hogea, "Assessment of the effects induced by two triterpenoids on liver mitochondria respiratory function isolated from aged rats," Revista de Chimie, vol. 66, pp. 1707-1710, 2015.

[80] G. D. Liyanaarachchi, J. K. R. R. Samarasekera, K. R. R. Mahanama, and K. D. P. Hemalal, "Tyrosinase, elastase, hyaluronidase, inhibitory and antioxidant activity of Sri Lankan medicinal plants for novel cosmeceuticals," Industrial Crops and Products, vol. 111, pp. 597-605, 2018.

[81] R. Boran, "Investigations of anti-aging potential of Hypericum origanifolium Willd. for skincare formulations," Industrial Crops and Products, vol. 118, pp. 290-295, 2018.

[82] S. Briganti, E. Camera, and M. Picardo, "Chemical and instrumental approaches to treat hyperpigmentation," Pigment Cell Research, vol. 16, no. 2, pp. 101-110, 2003.

[83] T. Finkel and N. J. Holbrook, "Oxidants, oxidative stress and the biology of ageing," Nature, vol. 408, no. 6809, pp. 239247, 2000.

[84] P. Gkogkolou and M. Böhm, "Advanced glycation end products: key players in skin aging?," Dermato-Endocrinology, vol. 4, no. 3, pp. 259-270, 2012.

[85] D. Harraan, "Aging: A Theory Based on Free Radical and Radiation Chemistry," Journal of Gerontology, vol. 11, no. 3, pp. 298-300, 1956.

[86] Y. S. Hori, A. Kuno, R. Hosoda, and Y. Horio, "Regulation of FOXOs and p53 by SIRT1 modulators under oxidative stress," PLoS One, vol. 8, no. 9, article e73875, 2013.

[87] S. Shanbhag, A. Nayak, R. Narayan, and U. Y. Nayak, "Antiaging and sunscreens: paradigm shift in cosmetics," Advanced Pharmaceutical Bulletin, vol. 9, no. 3, pp. 348-359, 2019.

[88] H. G. Breunig, M. Weinigel, and K. König, "In vivo imaging of $\mathrm{ZnO}$ nanoparticles from sunscreen on human skin with a mobile multiphoton tomograph," Bionanoscience, vol. 5, no. 1, pp. 42-47, 2015.

[89] A. C. Janaki, E. Sailatha, and S. Gunasekaran, "Synthesis, characteristics and antimicrobial activity of $\mathrm{ZnO}$ nanoparticles," Spectrochimica Acta Part A: Molecular and Biomolecular Spectroscopy, vol. 144, pp. 17-22, 2015.

[90] M. M. Modena, B. Rühle, T. P. Burg, and S. Wuttke, "Nanoparticle characterization: what to measure?," Advanced Materials, vol. 31, article 1901556, 2019. 
[91] S. Heim and F. Mitelman, Cancer cytogenetics: chromosomal and molecular genetic aberrations of tumor cells, John Wiley \& Sons, 2015.

[92] M. Alaraby, B. Annangi, A. Hernández, A. Creus, and R. Marcos, "A comprehensive study of the harmful effects of $\mathrm{ZnO}$ nanoparticles using Drosophila melanogaster as an in vivo model," Journal of Hazardous Materials, vol. 296, pp. 166-174, 2015.

[93] P. Chen, H. Wang, M. He, B. Chen, B. Yang, and B. Hu, "Size-dependent cytotoxicity study of $\mathrm{ZnO}$ nanoparticles in HepG2 cells," Ecotoxicology and Environmental Safety, vol. 171, pp. 337-346, 2019.

[94] A. F. Ismail, M. M. Ali, and L. F. Ismail, "Photodynamic therapy mediated antiproliferative activity of some metal-doped $\mathrm{ZnO}$ nanoparticles in human liver adenocarcinoma HepG2 cells under UV irradiation," Journal of Photochemistry and Photobiology B: Biology, vol. 138, pp. 99-108, 2014.

[95] P. B. Ezhuthupurakkal, S. Ariraman, S. Arumugam et al., "Anticancer potential of $\mathrm{ZnO}$ nanoparticle-ferulic acid conjugate on Huh-7 and HepG2 cells and diethyl nitrosamine induced hepatocellular cancer on Wistar albino rat," Nanomedicine: Nanotechnology, Biology and Medicine, vol. 14, no. 2, pp. 415-428, 2018.

[96] A. Iswarya, B. Vaseeharan, M. Anjugam et al., "Multipurpose efficacy of $\mathrm{ZnO}$ nanoparticles coated by the crustacean immune molecule $\beta$-1, 3-glucan binding protein: toxicity on HepG2 liver cancer cells and bacterial pathogens," Colloids and Surfaces B: Biointerfaces, vol. 158, pp. 257-269, 2017.

[97] E. H. Ismail, A. Saqer, E. Assirey, A. Naqvi, and R. Okasha, "Successful green synthesis of gold nanoparticles using a Corchorus olitorius extract and their antiproliferative effect in cancer cells," International Journal of Molecular Sciences, vol. 19, no. 9, p. 2612, 2018.

[98] D. Nayak, S. Pradhan, S. Ashe, P. R. Rauta, and B. Nayak, "Biologically synthesised silver nanoparticles from three diverse family of plant extracts and their anticancer activity against epidermoid A431 carcinoma," Journal of Colloid and Interface Science, vol. 457, pp. 329-338, 2015. 